9 - ORIGINAL ARTICLE

WOUND HEALING

\title{
Oil mixes omega 9, 6 and 3, enriched with seaweed, promoted reduction of thermal burned modulating NF-kB and Ki-6 $7^{1}$
}

\author{
Ana Paula Bomfim Soares Campelo ${ }^{\mathrm{I}}$, Márcio Wilker Soares Campelo ${ }^{\mathrm{I}}$, Gerly Anne de Castro Brito ${ }^{\mathrm{II}}$, Francisco Vagnaldo Fechine \\ Jamacaru ${ }^{\text {III, }}$ Renata Ferreira de Carvalho Leitão ${ }^{\mathrm{IV}}$, Paulo Roberto Leitão de Vasconcelos ${ }^{\mathrm{V}}$ \\ DOI: http://dx.doi.org/10.1590/S0102-865020150060000009 \\ ${ }^{\mathrm{I}}$ Fellow PhD degree, Postgraduate Program in Surgery, Department of Surgery, Federal University of Ceara (UFC), Fortaleza-CE, Brazil. Scientific and \\ intellectual content of the study, technical procedures, acquisition and interpretation of data, histological examinations, manuscript writing. \\ IIPhD, Full Professor, Department of Morphology, UFC, Fortaleza-CE, Brazil. Acquisition and interpretation of data, histological examinations, critical \\ revision. \\ IIIMD, Department of Pharmacology, UFC, Fortaleza-CE, Brazil. Analysis and interpretation of data, critical revision. \\ ${ }^{\text {IV }} \mathrm{PhD}$, Associate Professor, Department of Morphology, UFC, Fortaleza-CE, Brazil. Acquisition and interpretation of data, histological examinations. \\ ${ }^{v} \mathrm{PhD}$, Head and Full Professor, Researcher 1A-CNPq, Postgraduate Program in Surgery, Department of Surgery, UFC, Fortaleza-CE, Brazil. Scientific \\ and intellectual content of the study, interpretation of data, manuscript writing, critical revision.
}

\begin{abstract}
PURPOSE: To examine the effects of the oil mixes $(\omega-9, \omega-6$ and $\omega-3)$ in rats subjected to thermal burn. It was also aimed to assess whether the sources of $\omega 3$ would interfere with the effect of such mixes on the thermal injury.

METHODS: Thirty-six rats distributed into five groups: burned + water, burned + isolipid mix, burned + oil mix 1 (ALA), burned + oil mix 2 (ALA + EPA + DHA of fish) and burned + oil mix 3 (ALA + DHA from seaweed). The thermal injury was involving total thickness of skin. After the burns animals received the oil mixes for seven days. The lesions were evaluated by immunohistochemistry. RESULTS: Animals receiving mix 3 showed a smaller extension of the thermal injury as compared to those that were supplemented with other oils mixes. Expression of Ki-67 in the receiving Mix 3 increased as compared to all the other groups. Animals supplemented with mix 3 were able to inhibit NF-kB in injured tissue.
\end{abstract}

CONCLUSION: Rats received oil mix in which the source of $\omega 3$ (ALA+DHA of seaweed) showed inhibition of NF- $\mathrm{kB}$, increase in cell proliferation, and reduction the extension of thermal lesion.

Key words: Burn. Fatty Acids. Seaweed. Docosahexenoic Acid. alpha-Linolenic Acid. Rats. 


\section{Introduction}

Burns are one of the most widespread injuries in accidents and remain a global public health issue ${ }^{1}$. The burn wound is a continuous and severe threat against the rest of the body due to invasion of infectious agents, antigen challenge, and repeated additional trauma caused by wound cleaning ${ }^{2-4}$.

The sequence of events repairing the wound is categorized into four overlapping phases: inflammation, proliferation, tissue remodeling and scar maturation ${ }^{5}$. Burn wound healing involves a sequence of molecular and cellular events including inflammation, cell migration, angiogenesis, extracellular matrix synthesis, and re-epithelialization ${ }^{6}$.

Nutrition is a hallmark of burn care because of large wound burden and severe catabolic state that accompanies severe burn injuries. The importance of the role of nutrition in wound healing is an area that has been widely explored over the last decade $^{7-10}$.

Currently, the dietary balance of lipid has motivated several investigations. In patients with the metabolic disorders, the balance between dietary lipids may modulate oxidative stress response. The relationship between the types of polyunsaturated fatty acids feeding ${ }^{11}$ affects the synthesis of eicosanoids that act as intermediate messengers of growth factors, controlling growth and differentiation of epithelial cells ${ }^{12}$.

Several experimental studies in rats have been carried out using polyunsaturated fatty acids, highlighting benefits of dietary supplementation after ultraviolet light exposure ${ }^{13}$ or hot liquid ${ }^{14-15}$.

However, this appears to be the first work that involves the simultaneous administration of omega $9(\omega-9)$, omega 6 ( $\omega-6)$ and omega $3(\omega-3)$, with high ratios of $\omega-9: \omega-6$ and low ratios of $\omega-6: \omega-3$, as well as three different sources of $\omega-3$ (ALA (alpha linolenic acid), EPA (eicosapentaenoic acid) + DHA (docosahexenoic acid) from fish oil, and DHA from algaes), to rats subjected to burning by thermal conduction.
In the present study the mixtures of oils were offered at nutraceutical concentrations with low ratio of $\omega-6: \omega-3$ and high ratio $\omega-9: \omega-6$ as presented in other biological situations ${ }^{16-18}$.

The hypothesis of this study are that the use of combinations containing different proportions of omega 3, 6 and 9 amino acids may have a effect in the process of cell proliferation (re-epithelialization) and oxidative stress of skin burned. It was also aimed to assess whether not only the proposed oil mixes, but what source of $\omega-3$ would interfere in the effect.

\section{Methods}

All surgical procedures and animal handling were conducted in accordance with Council for International organization of Medical Sciences (CIOMS) and the Guide for the Care and Use of Laboratory Animals from the Brazilian College of Animal Experimentation, after approval by the local ethics committee (UFC) (protocol \#37/10). The study was designed to minimize the number of animals required for the experiments. The animals were housed in polypropylene cages at ambient temperature of $24^{\circ} \mathrm{C}$ on a $12 \mathrm{~h}$ light-dark cycle.

Male Wistar rats (Rattus norvegius albinus), weighing 250-270g were under standard housing conditions with free access to water and chow, and were randomly assigned to five groups of six animals each: Burn-water $(\mathrm{B}+\mathrm{W})$; Burn-Isolipidic Mix $(\mathrm{B}+\mathrm{I})$; Burn-Mix 1 (B+M1); Burn-Mix 2 (B+M2); Burn-Mix 3 (B+M3). The groups $\mathrm{B}+\mathrm{M} 1, \mathrm{~B}+\mathrm{M} 2$ and $\mathrm{B}+\mathrm{M} 3$ received oily mixtures of $\omega-6 / \omega-3$ (1.4:1 ratio) and $\omega-9 / \omega-6$ (3.4:1 ratio), differing only in the source of $\omega-3$ : Mix 1 ( $\omega-3$ alpha-linolenic acid), Mix 2 ( $\omega$-3 alphalinolenic, docosahexaenoic and eicosapentaenoic acids) and Mix 3 ( $\omega-3$ alpha-linolenic and docosahexaenoic acids). The $\mathrm{B}+\mathrm{I}$ group received isolipidic mixture of $\omega-6 / \omega-3$ (8:1 ratio) and $\omega-9 / \omega-6(0.4: 1$ ratio). Mixtures are detailed on Table 1 . The administered dose of each mixture corresponded to $1.2 \mathrm{~g}$ of oil/ $\mathrm{Kg}$ of animal body, by orogastric administration, daily for seven consecutive days.

TABLE 1 - Division of groups and the mixtures composition (oils and ratio) with their respective sources of $\omega-3$.

\begin{tabular}{|c|c|c|c|c|}
\hline \multirow[t]{2}{*}{ Groups } & \multirow[t]{2}{*}{ Composition } & \multirow[t]{2}{*}{$\omega-3$ sources } & \multicolumn{2}{|c|}{ Ratio } \\
\hline & & & $\omega-6: \omega-3$ & $\omega-9: \omega-6$ \\
\hline Burn-Water (B-W) & Water & - & - & - \\
\hline Burn-Mix 1 (B-M1) & $\omega-9$ (olive) $+\omega-6($ canola $)+\omega-3$ & ALA(linseed) & $1.4: 1$ & $3.4: 1$ \\
\hline Burn-Mix 2 (B-M2) & $\omega-9$ (olive) $+\omega-6($ canola $)+\omega-3$ & $\mathrm{ALA}+\mathrm{EPA}+\mathrm{DHA}$ (fish) & $1.4: 1$ & $3.4: 1$ \\
\hline
\end{tabular}

Note: Mix=mixture; $\mathrm{ALA}=$ alpha-linolenic acid; $\mathrm{DHA}=$ docosahexaenoic acid and $\mathrm{EPA}=$ eicosapentaenoic acids. 


\section{Burns}

In the first day, the rats were anesthetized with an intramuscular injection of ketamine hydrochloride $(90 \mathrm{mg} /$ $\mathrm{kg})$ and xylazine $(10 \mathrm{mg} / \mathrm{kg})$ and immediately before inflicting the burn, the area was shaved with a standard electric shaving machine to obtain a smooth surface and hairless skin, two 10 x $10 \mathrm{~mm}$ squares were outlined with a sterile surgical marker on each side and along the vertebral column using a prepared template (an X-ray film with a $10 \times 10 \mathrm{~mm}$ grid) positioned between the thoracic and abdominal limbs. The dorsal skin was surgically prepared with successive applications of $2 \%$ chlorhexidine scrub. A previously described model ${ }^{19-20}$ was used with some modifications. The original tip of an ordinary $40 \mathrm{~W}$ soldering iron was replaced with tip and square $10 \times 10$ $\mathrm{mm}$ copper plate. An electronic temperature controller with a thermocouple type feedback sensor was connected $2 \mathrm{~mm}$ above the plate tip in order to allow precise optimal temperature monitoring at the tip of the instrument. Additionally, a digital multimeter with a $\mathrm{K}$ type thermocouple was fixed to the copper plate to assure real time optimal control of the temperature applied to the skin (surface counter). The desired stamp temperature $\left(200^{\circ} \mathrm{C}\right)$ was reached 5 min after switching on the electric current. The device was positioned vertically under its own weight $(85 \mathrm{~g})$ and applied to each skin burn site during nine seconds to inflict the burns as outlined. Immediately after each burn injury, the respective wound was cooled off during $1 \mathrm{~min}$ with gauze embedded in isotonic saline at $22^{\circ} \mathrm{C}$, as described elsewhere ${ }^{21}$. The plate produced a burn area of approximately 1 $\mathrm{cm}^{2} /$ wound. Four burns were produced on each animal $\left(4 \mathrm{~cm}^{2} /\right.$ animal) leaving approximately $1 \mathrm{~cm}$ intact skin between burned areas. Following one hour of the procedure, the burns injuries were photographed (see macroscopic analysis for details) and the animals received water, or isolipidic oil mix, or one specific mix of oils for each respective group, and were returned to their individual cages for recovery with free access to rat chow and tap water. Analgesia was administered during 24h after burn injury by adding $30 \mathrm{mg}$ codeine phosphate hemihydrate to 500 $\mathrm{ml}$ tap water.

\section{Histopathology}

At the end of the experiments (seventh day) all animals were killed by an overdose of anesthetics (ketamine+xylazine). Tissue samples were collected from the dorsum with a surgical blade, removing skin fragments $(20 \mathrm{~mm}$ x $5 \mathrm{~mm})$, including the central scar, adjacent healthy tissue and underlying panniculus carnosus muscle. Tissue samples were fixed in formalin for 24 hours before being transferred to $70 \%$ ethanol solution. Further processing included paraffin embedding and sectioning, to generate 5 - $\mu \mathrm{m}$-thick tissue coronal sections to be mounted on glass slides. The slides were stained using hematoxylin and eosin. The extent of skin damage was assessed by a pathologist, who was not aware of which treatment was applied to the animals, using a light microscope (Olympus, X100).

\section{Immunohistochemistry}

Immunohistochemistry for Ki-67 (cell proliferation), NF- $\kappa$ B p50 (NLS) and HNE-J (lipidic peroxidation) was performed on skin tissue using the streptavidin-biotinperoxidase method in formalin-fixed, paraffin-embedded tissue sections ( $4 \mu \mathrm{m}$ thick), mounted on poly-L-lysinecoated microscope slides. The sections were deparaffinized and rehydrated through xylene and graded alcohols. After antigen retrieval, endogenous peroxidase was blocked (15 min) with 3\% ( $v \mathrm{v}-1)$ hydrogen peroxide and washed in phosphate-buffered saline (PBS). Sections were incubated overnight $\left(4^{\circ} \mathrm{C}\right)$ with primary rabbit anti-Ki-67 and rabbit anti-NF- $\kappa \mathrm{B}$, mouse antiHNE-J antibody (individual slide for each antibody) diluted 1:200 in PBS plus bovine serum albumin (PBS-BSA). The slides were then incubated with biotinylated goat anti-rabbit or anti-mouse (for each primary antibody respectively) diluted 1:400 in PBS-BSA. After washing, the slides were incubated with avidin-biotin-horseradish peroxidase conjugate (Strep ABC complex by Vectastain-ABC Reagent and peroxidase substrate solution) for $30 \mathrm{~min}$, according to the Vectastain protocol. Ki-67 and NF- $\mathrm{KB}$ and HNE-J were visualized with the chromogen 3,3'diaminobenzidine (DAB). Negative control sections were processed simultaneously as described above but with the first antibody being replaced by PBS-BSA 5\%. None of the negative controls showed immunoreactivity. Slides for HNE-J were counterstained with Harry's hematoxylin, dehydrated in a graded alcohol series, cleared in xylene and cover slipped.

\section{Acquisition and processing of the immunohistochemistry images}

Digital images of histological samples were acquired in standard fashion using a light microscope (Olympus, x100) fitted with a digital camera. The procedure included an initial 
scan of the histological preparation at $\mathrm{x} 40$ magnification in order to identify areas with increased density (hot spots) of the structures of interest (starting and ending edge of the burned zone containing the tissue of re-epithelialization). Three hot spots selected for each sample were then color-scanned at $\mathrm{x} 100$ magnification. Images were saved as Windows ${ }^{\circledR}$ bitmaps measuring $640 \times 480$ pixels.

Images were processed by Morphometric Analysis System (SAMM), a software developed specifically for this purpose $^{22}$. The system was previously adjusted to recognize the color spectrum of the structures of interest, according to the staining technique employed. This step enabled the software to automatically identify and segment the structures of interest (separating them from the other components of the histological preparation) in both full images and user-defined regions of interest (ROI). However, interactive segmentation (making changes in segmentation parameters) remained an option whenever the automatic mode was deemed inadequate. Following segmentation, the software provided the quantification of the structure of interest in the image or ROI by calculating the area density, that is the quotient between the area occupied by the structure of interest and the total area analyzed.

\section{Statistical analysis}

After a Kolmogorov-Smirnov test of normality, data were submitted to one-way analysis of variance followed by Tukey's multiple comparison test. Parametric data were expressed as mean $\pm \mathrm{SD}$. The level of statistical significance was set at $5 \%$.

\section{Results}

\section{Microscopic analysis}

On the seventh day there was smaller extension of the lesion only in the burn-Mix 3 as compared to extension observed in the burn-water group $(\mathrm{p}<0.05)$. There was no difference between burn-water, burn-isolipidic, burn-mix 1 and burn-mix 2 group, see Figure 1.

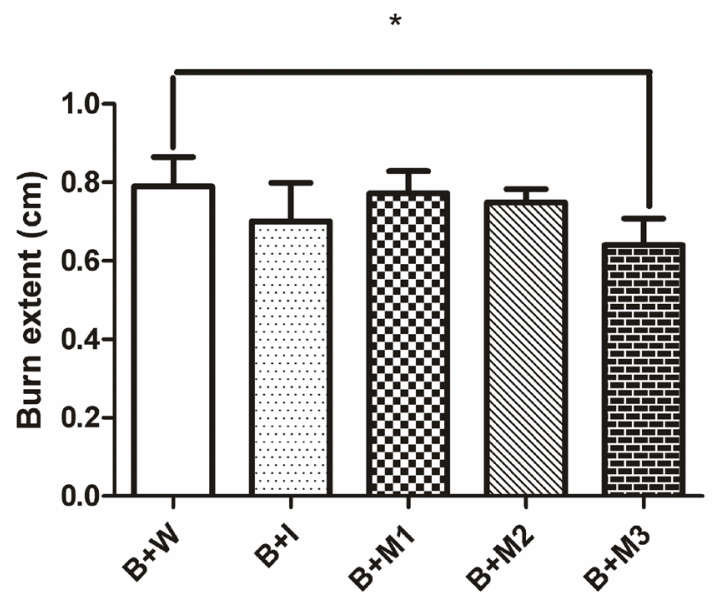

FIGURE 1 - Burn extension in $\mathrm{cm}$ on the seventh day for each group, visualized with optical microscopic (magnification x10). Results presented as mean and standard deviation. $(n=6),{ }^{*} p<0.05$. Abbreviations: $\mathrm{B}+\mathrm{W}=$ group burned and administered water; $\mathrm{B}+\mathrm{I}=$ group burned and administered isolipdic mixture; $\mathrm{B}+\mathrm{M} 1$ = group burned and administered mixture 1 of oils; $\mathrm{B}+\mathrm{M} 2$ = group burned and administered mixture 2 of oils; $\mathrm{B}+\mathrm{M} 3$ = group burned and managed mixture 3 of oils.

\section{Quantitative analysis of immunohistochemistry}

There was a higher detection (positively stained) of antibody Ki-67 antibody in burn-mix 3 group than burn-water group $(\mathrm{p}<0.05)$. There was however no statistical significant differences when the burn-water group was compared to other groups, see Figure $2 \mathrm{~A}$ and $\mathrm{B}$.

There was less detection (positively stained) of antibody NF-kB in the Mix 3 Group than burn-water group $(p<0.05)$. There were no significant statistical differences when the burn-water group was compared to other groups, see Figure 3 A and B.

There were no significant statistical differences in detection (positive staining) of antibodies HNE-J between the groups $(\mathrm{p}>0.05)$. 
A)
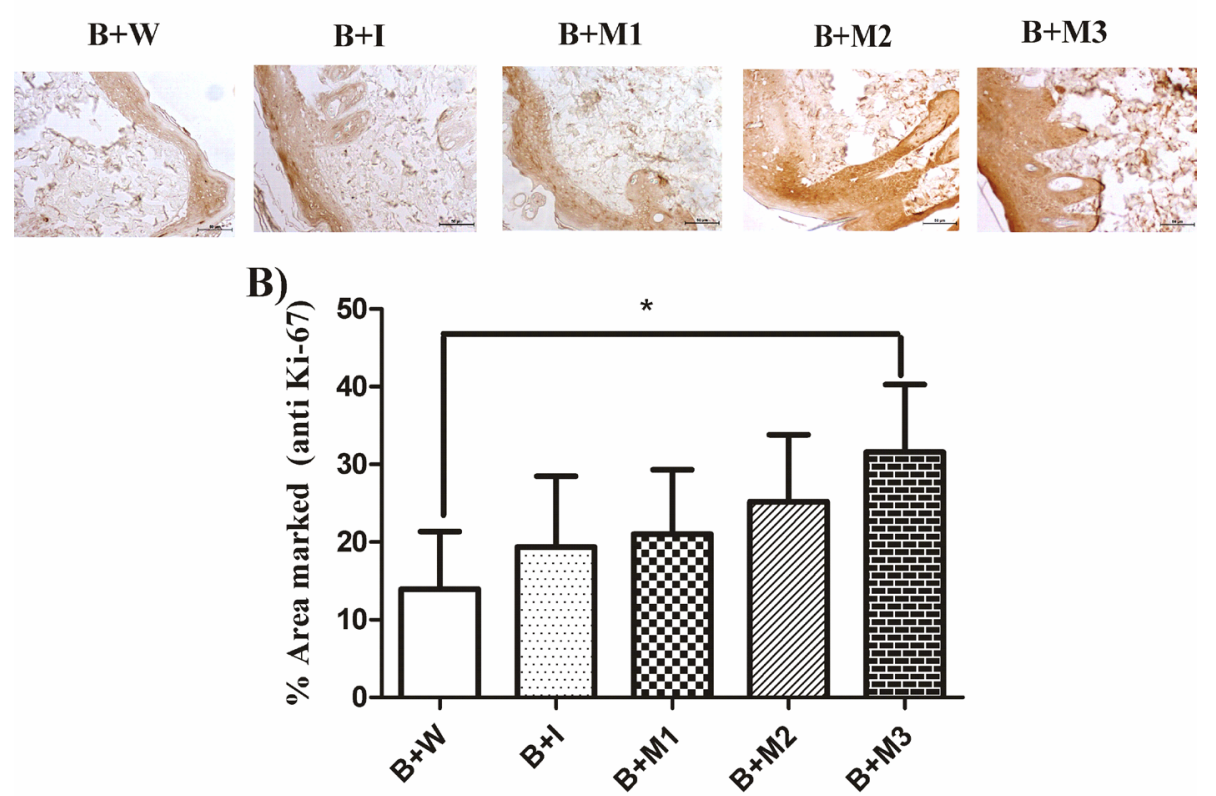

FIGURE 2 - A) Representative image of Immunohistochemical for anti-Ki-67 of the skin of an animal in each group. B) Percentage of area marked by anti-body Ki-67. Results presented as mean and standard deviation. $(n=6),{ }^{*} \mathrm{p}<0.05(\mathrm{~B}+\mathrm{W}$ vs. $\mathrm{B}+\mathrm{M} 3)$. Abbreviations: $\mathrm{B}+\mathrm{W}=$ group burned and administered water; $\mathrm{B}+\mathrm{I}=$ group burned and administered isolipdic mixture; $\mathrm{B}+\mathrm{M} 1$ = group burned and administered mixture 1 of oils; $\mathrm{B}+\mathrm{M} 2=$ group burned and administered mixture 2 of oils; $\mathrm{B}+\mathrm{M} 3$ = group burned and managed mixture 3 of oils.

A)

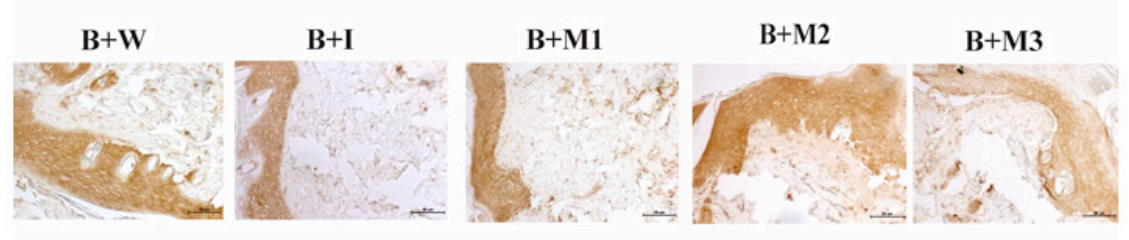

B)

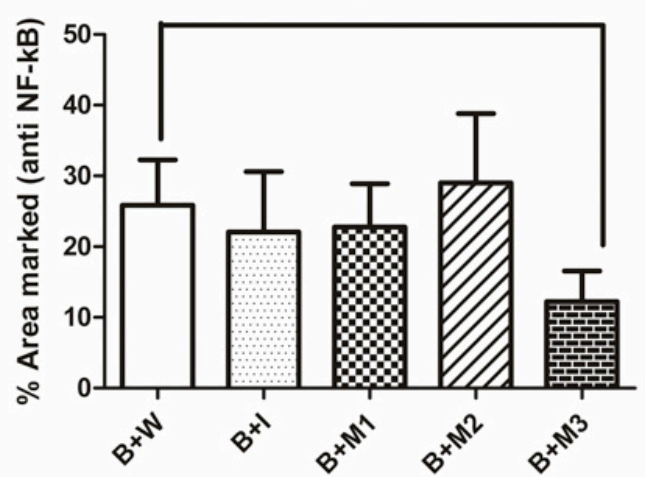

FIGURE 3 - A) Representative image of Immunohistochemical for anti- anti-NF- $\mathrm{B}$ of the skin of an animal in each group. B) Percentage of area marked by anti-body anti-NF- $\kappa \mathrm{B}$. Results presented as mean and standard deviation. $(\mathrm{n}=6),{ }^{*} \mathrm{p}<0.05(\mathrm{~B}+\mathrm{W}$ vs. $\mathrm{B}+\mathrm{M} 3)$. Abbreviations: $\mathrm{B}+\mathrm{W}=$ group burned and administered water; $\mathrm{B}+\mathrm{I}=$ group burned and administered isolipdic mixture; $\mathrm{B}+\mathrm{M} 1$ = group burned and administered mixture 1 of oils; $\mathrm{B}+\mathrm{M} 2$ = group burned and administered mixture 2 of oils; $\mathrm{B}+\mathrm{M} 3$ = group burned and managed mixture 3 of oils.

\section{Discussion}

The present study was designed to examine the effects of oils mixtures $\omega-9, \omega-6$ and $\omega-3$, as well as which type of the $\omega-3$ source (ALA, EPA and DHA) may influence cell proliferation and stress oxidative in rat skin burned by direct conduction.

Experimental model of burns in animals have been an essential tool for the study of the pathophysiology of skin lesions 
that may also occur in humans, which may help to develop new methods of treatment ${ }^{24-25}$.

Burn lesions were induced by energy transfer using a copper plate in direct contact with the skin at continuous high temperature $\left(200^{\circ} \mathrm{C}\right)$ electronically controlled, resulting in skin thermal injury of total thickness (epidermis, dermis, hypodermis and musculature) with lesion of the hair follicles and healing from the periphery to the center of the lesion. This method was used in this study due to its repeatability and uniformity ${ }^{20}$.

The Wistar rat was chosen because it is a small animal, enabling easy standardization with regard to age, weight, sex, housing, feeding, cleaning care and experimental manipulation. In addition, these animals have been used in various experimental models to evaluate treatment of burns ${ }^{25-29}$.

The anesthetic method proved to be satisfactory by the relative ease induction and maintenance of the anesthetic plan, little volume administered and quick recovery. It was performed good analgesia with codeine in the water evidenced by the absence of respiratory complications or accidental deaths.

The site chosen for the accomplishment of the burns was the dorsal area of animals, in accordance with the observations of several researchers, who consider the skin of the back as the best place for experimental lesion, avoiding irritation on contact with saliva and self cannibalism ${ }^{30-31}$

Pharmaconutrients or "nutraceuticals" are isolated or combined nutrients that, at pharmacological doses, modify the biological response of the host. The most commonly used nutraceuticals are anti-inflammatory $\omega-3$ fatty acids (EPA and DHA), glutamine, arginine and nucleotides ${ }^{32}$.

The present study appears to represent the first demonstration that mixtures of oils containing low ratio of $\omega-6$ to $\omega-3$ and high ratio of $\omega-9$ to $\omega-6$ with nutraceutical concentrations, evaluated in a burn model by direct conduction in rats, resulted in increased re-epithelialization and lower marking of NF- $\kappa \mathrm{B}$ stain, both events observed as omega 3 source type dependent.

Currently, there is solid evidence supporting the concept that the intake of nutrients with a specific focus may improve the final results by modulating the immune, metabolic and oxidative stress response $\mathrm{e}^{33-36}$.

Western societies have a diet with a ratio $\omega-6: \omega-3$ between 15:1 and 16,7:17 . In general, in an American diet, individuals consume fatty acids as follows: $89 \%$ is linoleic acid (AL) whereas only $9 \%$ is ALA. However the ideal ratio $\omega-6: \omega-3$ would vary between $1: 1$ and 4:177,18,37,38.

Marine fish oils have high $\omega-3$ content, mostly in the form EPA and DHA ${ }^{33}$. Studies show that a high ratio $\omega-6: \omega-3$, such as those mentioned in the above paragraph, promotes various diseases due to the increased production of NFk-B and inflammatory factors [16]. On the other hand, increased consumption $\omega-3$ (i.e. with a decrease in the ratio of $\omega-6: \omega-3)$ has opposite effects.

Vassiliou et al..$^{39}$ demonstrated in vitro that the oleic acid ( $\omega-9)$ reduces in a dose-dependent way oxidative stress. The higher concentration of $\omega-9$, the greater antioxidant effect.

It is known that the $\omega-3$ fatty acid can come from different sources, therefore, in this work there were used three mixtures of oils with $\omega-3$ different sources: Mixes 1 (ALA), mix 2 (ALA + $\mathrm{EPA}+\mathrm{DHA}$ from fish), mix 3 (ALA + DHA from seaweed). A mixture of isocaloric oils, with $\omega-9: \omega-6$ ratio of $0.4: 1$ and $\omega-6: \omega-3$ ration of $8: 1$, was used as isolipidic neutral mix, as it should not promote neither anti-oxidant or anti-inflammatory action. There was also a control group that received only water (zero fat).

On the seventh day of the oil intake burned rats which received $\omega$-3 from seaweed (M3 - DHA) showed a reduction in the lesion area as compared to those who received water, neutral isolipidic control, and other mixtures with different sources of $\omega-3$ (Mix 1 - ALA, Mix 2 - ALA+ EPA + DHA from fish oil). The burn extension was considered edge-to-edge of re-epithelialization without interference of the crusts.

To study cellular proliferation, tissue staining of the nuclear protein marker Ki-67 was used. This protein is structurally associated with chromatin to develop function in cell proliferation and is present in the G1, S, G2 and M phases of the cell cycle, and absent in the cells during G0 phase. The monoclonal antibody against Ki-67 was obtained by Gerdes et $a l .{ }^{40}$. It reacts with a proliferating cell nuclear antigen ${ }^{41}$ and has previously been used in an experimental model of burn showing positive correlation between cell proliferation and wound healing in burned mice ${ }^{42}$. Mix 3 was the only group to show increased cell proliferation, as regard to Ki-67 tissue staining which is consistent with the results obtained by the microscopy analysis that demonstrated reduction in the burned extent.

Immunohistochemical assessment, in this study, was carried out quantitatively using the software developed specifically for morphometric study already used in other similar works ${ }^{19-20}$. This fully automated method allows absence of interference from the observer after the acquisition of the images as recommended by Dornelas ${ }^{22}$.

The families of $\omega-3$ and $\omega-6$ use the same enzyme system, competing for enzymes in common. This competition alters the entire metabolism of the production of eicosanoids, such as PG, TX and LT. The eicosanoids from the metabolism of AGPIs $\omega-6$ are pro-inflammatory mediators, while those from the metabolism of 
$\omega-3$ are anti-inflammatory. Some effects of AGPIs on immune and inflammatory systems are independent of eicosanoids generation. Studies emphasize that the series AGPIs $\omega-3$ affect immune functions. These acids present a suppressor effect, inhibiting the proliferation of lymphocytes, antibody production, the production of pro-Inflammatory cytokines and others nuclear transcription molecules ${ }^{11,43-45}$.

One of the most important links that self-perpetuating cycle of inflammation is NF- $\mathrm{BB}$. It is a nuclear transcription factor (protein family) found in all cell types consisting of five subunits that act as heterodimers and homodimers that is involved in responses to stimuli such as stress, cytokines, free radicals, ultraviolet radiation and burns ${ }^{43,46}$. It acts basically as the "on/ off" switch to the cell to generate inflammatory mediators. When activated, act as a transcription factor for a vast number of genes involved in immunoregulation, growth regulation and inflammation ${ }^{47}$. Activation of NF-kB is controlled by the inhibitor of kappa B (IkB) family of proteins. IkB proteins suppress NF$\mathrm{kB}$ activity by binding to its protein subunits, preventing its translocation to the nucleus ${ }^{48}$. Once activated, NF-kB induces expression of inflammation-related signaling molecules, some of which are themselves responsible for NF-kB activation. Just a few examples of inflammation-related proteins whose expression is under control of NF-kB include cytokines.

Omega-3 fatty acids have been shown to inhibit NF-kB activation, and sometimes expression, in a number of cell lines and animal models. A study in HR-1 mice, a hairless mouse strain used to study skin disorders, showed that topical application of DHA reduces UVB radiation-induced $\mathrm{IkB}$ phosphorylation and subsequent NF-kB activation. The authors attributed this to a decrease in phosphorylation of mitogen and stress-activated kinase-1 (MSK1), a downstream target of the MAPK/ERK signaling pathway and known activator of NF-Kb ${ }^{49,50}$.

The $\omega-3$ fatty acids are able to stabilize and influence NF- $\kappa \mathrm{B}$ signal transduction and gene expression by the level of EPA and DHA acquired by diet ${ }^{44,45}$. The EPA and DHA appear to help the resolution of inflammation and the production of potent anti-inflammatory molecules called resolvins. In the present study, only in M3 group, where omega-3 source was seaweed, there was observed lower immunohistochemical marking of NF- $\mathrm{KB}$ as compared to all other groups. Interestingly this source of $\omega-3$ is rich in doxohexanoic acid.

To evaluate the antioxidant action of mixtures of oils with high ratio of $\omega-9: \omega-6$ and low ratio $\omega-6: \omega-3$ an immunohistochemical marker with the antibody anti-4hydroxinonenal (Anti-HNE-J) was used. This antibody induces the production via lipid peroxidation of 4-hydroxinonenal, which is one of the mediators of cell death due to oxidative stress ${ }^{51,52}$. On the seventh day no difference was found among mixtures. Albeit in very different circumstances, the monounsaturated fatty acid oleic acid, present in the mixes studied, present theoretical antioxidant action, especially as regard to olive oil, which is rich in polyphenols. It may be possible that an anti-oxidant effect could occur in the early hours or days post-burn, and therefore future new experiments with earlier sampling should be performed.

\section{Conclusion}

Rats received oil mix in which the source of $\omega 3$ (ALA+DHA of seaweed) showed inhibition of NF- $\mathrm{KB}$, increase in cell proliferation, and reduction the extension of thermal lesion.

\section{References}

1. Golshan A, Patel C, Hyder AA. A systematic review of the epidemiology of unintentional burn injuries in South Asia. J Public Health (Oxf). 2013 Sep;35(3):384-96. doi: 10.1093/pubmed/fds102.

2. Upadhyay NK1, Kumar R, Mandotra SK, Meena RN, Siddiqui MS, Sawhney RC, Gupta A. Safety and healing efficacy of Sea Buckthorn (Hippophae rhamnoides L.) seed oil on burn wounds in rats. Food Chem Toxicol. 2009 Jun;47(6):1146-53. doi: 10.1016/j. fct.2009.02.002.

3. Singer AJ, Berruti L, Thode HC Jr, McClain SA. Standardized burn model using a multiparametric histologic analysis of burn depth. Acad Emerg Med. 2000 Jan;7(1):1-6. doi: 10.1111/j.15532712.2000.tb01881.x.

4. Arturson G. Pathophysiology of the burn wound and pharmacological treatment. The Rudi Hermans Lecture, 1995. Burns. 1996 Jun;22(4):255-74. doi:10.1016/0305-4179(95)00153-0.

5. Singer AJ, Clark RA. Cutaneous wound healing. N Engl J Med. 1999 Sep 2;341(10):738-46. doi: 10.1056/NEJM199909023411006.

6. Clark RA. Cutaneous tissue repair: basic biologic considerations. I. J Am Acad Dermatol. 1985 Nov;13(5 Pt 1):701-25. PMID: 2416789.

7. Lakos G, Takagawa S, Chen SJ, Ferreira AM, Han G, Masuda K, Wang XJ, DiPietro LA, Varga J. Targeted disruption of TGF-beta/ Smad3 signaling modulates skin fibrosis in a mouse model of scleroderma. Am J Pathol. 2004 Jul;165(1):203-17. doi: 10.1016/ S0002-9440(10)63289-0.

8. Medlin S. Nutrition for wound healing. Br J Nurs. 2012 Jun 28-Jul 11;21(12):S11-2,S14-5. doi: 10.12968/bjon.2012.21.Sup12.S11.

9. Oner OZ, Oğünç AV, Cingi A, Uyar SB, Yalçin AS, Aktan AO. Whey feeding suppresses the measurement of oxidative stress in experimental burn injury. Surg Today. 2006;36(4):376-81. doi: 10.1007/s00595-005-3166-5.

10. Sen S, Greenhalgh D, Palmieri T. Review of Burn Research for the Year 2010. J Burn Care Res. 2012 Sep-Oct;33(5):577-86. doi: 10.1097/BCR.0b013e3182644fba.

11. Calder PC. Long-chain n-3 fatty acids and inflammation: potential application in surgical and trauma patients. Braz J Med Biol Res. 2003 Apr;36(4):433-46. doi: 10.1590/S0100-879X2003000400004.

12. Capone LS, Bagga D, Glaspy J. Relationship between omega-3 and omega-6 fatty acid ratios and breast cancer. Nutrition. 1997 Sep;13(9):822-4. doi: 10.1016/S0899-9007(97)00199-8. 
13. Lu SL, Jin SW, Zhang J, Shigeo I, Hideaki S, Liao ZJ, Shi JX. An experimental study on the effects of postburn dietary supplementation of enhanced nutrients. Zhonghua Shao Shang Za Zhi. 2003 Aug;19(4):197-201. PMID: 14514396.

14. Zhang M, Fritsche KL. Fatty acid-mediated inhibition of IL-12 production by murine macrophages is independent of PPARgamma. Br J Nutr. 2004 May;91(5):733-9. doi: 10.1079/BJN20041096.

15. Xu QL, Cai C, Qi WW, Xia ZG, Tang YZ. Influence of omega-3 polyunsaturated fatty acids on inflammation-related parameters in lung tissue of rats with severe scald. Zhonghua Shao Shang Za Zhi. 2011 Oct;27(5):358-62. PMID: 22224257.

16. Allayee H, Roth N, Hodis HN. Polyunsaturated fatty acids and cardiovascular disease: implications for nutrigenetics. J Nutrigenet Nutrigenomics. 2009;2(3):140-8. doi: 10.1159/000235562.

17. Simopoulos AP. The importance of the ratio of omega-6/omega-3 essential fatty acids. Biomed Pharmacother. 2002 Oct;56(8):365-79. PMID: 12442909.

18. Simopoulos AP. The importance of the omega-6/omega- 3 fatty acid ratio in cardiovascular disease and other chronic diseases. Exp Biol Med (Maywood). 2008 Jun;233(6):674-88. doi: 10.3181/0711-MR311.

19. Mesquita CJ, Leite JA, Fechine FV, C Rocha JL, Leite JG, Leite Filho JA, Barbosa Filho RA. Burns. Effect of imiquimod on partialthickness burns. Burns. 2010 Feb;36(1):97-108. doi: 10.1016/j. burns.2009.04.022.

20. Campelo AP, Campelo MW, Britto GA, Ayala AP, Guimarães SB, Vasconcelos PR. Um modelo animal aperfeiçoado para estudo de queimaduras superficiais e profundas da pele. Acta Cir Bras. 2011;26 Suppl 1:38-4. doi: 10.1590/S0102-86502011000700008.

21. Jandera V, Hudson DA, de Wet PM, Innes PM, Rode H. Cooling the burn wound: evaluation of different modalites. Burns. 2000 May;26(3):265-70. doi: 10.1016/S0305-4179(99)00133-3.

22. Dornelas CA, Fechine-Jamacaru FV, Albuquerque IL, Magalhães HIF, Dias TA, Faria MHG, Alves MKS, Rabenhorst SHB, Almeida PRC, Lemos TLG, Castro JDV, Moraes MEA, Moraes MO. Angiogenesis inhibition by green propolis and the angiogenic effect of L-lysine on bladder cancer in rats. Acta Cir Bras. 2012 Aug;27(8):529-36. doi: 10.1590/S010286502012000800003.

23. Kaufman T, Lusthaus SN, Sagher U, Wexler MR. Deep partial skin thickness burns: a reproducible animal model to study burn wound healing. Burns. 1990 Feb;16(1):13-6. PMID: 2322389.

24. Aulick LH, Baze WB, Johnson AA, Wilmore DW, Mason ADJ A. large animal model of burn hypermetabolism. J Surg Res. 1981 Oct;31(4):281-7. PMID: 7289592.

25. Barbosa RCC, Guimarães SB, Vasconcelos PRC, Chaves CR, Vasconcelos PRL. Efeitos metabólicos da glutamina em ratos submetidos à queimadura por água fervente (escaldadura). Acta Cir Bras. 2003;18(6):527-33. doi: 10.1590/S0102-86502003000600008.

26. Davidson JM. Animal models for wound repair. Arch Dermatol Res. 1998 Jul;290 Suppl:S1-11. PMID: 9710378.

27. Livesey AS, Herndon DN, Hollyoak MA, Matalas SL, Nelson GS Transplanted acellular allograft dermal matrix. Transplantation. 1995 Jul 15;60(1):1-9. PMID: 7542811.

28. Srivastava A, Jennings LJ, Hanumadass M, Sethi S, Desagun E, Pavlis N. Xenogeneic acellular dermal matrix as a dermal susbstitute in rats. J Burn Care Rehabil. 1999 Sep-Oct;20(5):382-90. PMID: 10501326

29. Srivastava A, Desagun EZ, Jennings LJ, Sethi S, Phuangsab A, Hanumadass M. Use of porcine dermal matrix as a dermal substitute in rats. Ann Surg. 2001 Mar;233(3):400-8. PMID: 11224629.

30. Kashyap A, Beezhold D, Wiseman J, Beck WC. Effect of povidine iodine dermatologic ointment on wound healing. Am Surg. 1995 Jun;61(6):486-91. PMID: 7762895.
31. Hettiaratchy S, Dziewulski P. ABC of burns: pathophysiology and types of burns. BMJ. 2004 Jun 12;328(7453):1427-9. doi: 10.1136/ bmj.328.7453.1427.

32. Mesejo A, Sánchez AC, Arboleda SJA. Guidelines for specialized nutritional and metabolic support in the critically ill-patient. Update. Consensus of the Spanish Society of Intensive Care Medicine and Coronary Units-Spanish Society of Parenteral and Enteral Nutrition (SEMICYUC-SENPE): obese patient. Med Intensiva. 2011 Nov;35 Suppl 1:57-62. doi: 10.1016/S0210-5691(11)70012-2.

33. Alexander JW. Immunonutrition: The role of $\mathrm{w}-3$ fatty acids. Nutrition. 1998 Jul-Aug;14(7-8):627-33. doi: 10.1016/S08999007(98)00004-5.

34. Stables MJ, Gilroy DW. Old and new generation lipid mediators in acute inflammation and resolution. Prog Lipid Res. 2011 Jan;50(1):35-51. doi: 10.1016/j.plipres.2010.07.005.

35. Li HL, Chen LP, Hu YH, Qin Y, Liang G, Xiong YX, Chen QX. Crocodile oil enhances cutaneous burn wound healing and reduces scar formation in rats. Acad Emerg Med. 2012 Mar;19(3):265-73. doi: 10.1111/j.1553-2712.2012.01300.x.

36. Melo RB, Guimarães SB, Silva PG, Oriá RB, Melo JU, Vasconcelos PR. Antiperoxidative properties of oil mixes of high ratio Omega9:Omega-6 and low ratio Omega-6:Omega-3 after molar extraction in rats. Acta Cir Bras. 2014 Jun;29(6):371-5. doi: 10.1590/S010286502014000600004.

37. Schwingshackl L, Hoffmann G. Monounsaturated fatty acids and risk of cardiovascular disease: synopsis of the evidence available from systematic reviews and meta-analyses. Nutrients. 2012 Dec 11;4(12):1989-2007. doi: 10.3390/nu4121989.

38. Hayakawa S, Yoshikawa D, Ishii H, Tanaka M, Kumagai S, Matsumoto M, Hayashi M, Sugiura T, Hayashi K, Ando H, Amano T, Murohara T. Association of plasma omega-3 to omega-6 polyunsaturated Fatty Acid ratio with complexity of coronary artery lesion. Intern Med. 2012;51(9):1009-14. doi: 10.2169/ internalmedicine.51.7162.

39. Vassiliou EK, Gonzalez A, Garcia C, Tadros JH, Chakraborty G, Toney JH. Oleic acid and peanut oil high in oleic acid reverse the inhibitory effect of insulin production of the inflammatory cytokine TNF-alpha both in vitro and in vivo systems. Lipids Health Dis. 2009 Jun 26;8:25. doi: 10.1186/1476-511X-8-25.

40. Gerdes J, Schwab U, Lemke H, Stein H. Production of a mouse monoclonal antibody reactive with a nuclear antigen associated with cell proliferation. Int J Cancer. 1983 Jan 15;31(1):13-20. PMID: 6339421.

41. Urruticoechea A, Smith IE, Dowsett M. Proliferation marker Ki-67 in early breast cancer. J Clin Oncol. 2005 Oct 1;23(28):7212-20. doi: 10.1200/JCO.2005.07.501.

42. Kimura Y, Sumiyoshi M, Kawahira K, Sakanaka M. Effects of ginseng saponins isolated from Red Ginseng roots on burn wound healing in mice. Br J Pharmacol. 2006 Jul;148(6):860-70. doi: 10.1038/sj.bjp.0706794.

43. Clark JA, Coopersmith CM. Just the right amount of JNK - how NFkB and downstream mediators prevent burn-induced intestinal injury. Crit Care Med. 2007 May;35(5):1433-4. doi: 10.1097/01. CCM.0000262392.95282.D1

44. Calder PC, Grimble RF. Polyunsaturated fatty acids, inflammation and immunity. Eur J Clin Nutr. 2002 Aug;56 Suppl 3:S14-9. doi: 10.1038/sj.ejen.1601478.

45. Perez-Martinez P1, Garcia-Quintana JM, Yubero-Serrano EM, Tasset-Cuevas I, Tunez I, Garcia-Rios A, Delgado-Lista J, Marin C, Perez-Jimenez F, Roche HM, Lopez-Miranda J. Postprandial oxidative stress is modified by dietary fat: evidence from a human intervention study. Clin Sci (Lond). 2010 Jun 15;119(6):251-61. doi: $10.1042 / \mathrm{CS} 20100015$. 
46. Al-Kaisy AA, Salih Sahib A. Role of the antioxidant effect of vitamin $\mathrm{E}$ with vitamin $\mathrm{C}$ and topical povidone-iodine ointment in the treatment of burns. Ann Burns Fire Disasters. 2005 Mar 31;18(1):19-30. PMID: 21990974.

47. Li F, and Sethi G. Targeting transcription factor NF-kappaB to overcome chemoresistance and radioresistance in cancer therapy. Biochim Biophys Acta. 2010 Apr;1805(2):167-80. doi: 10.1016/j. bbcan.2010.01.002.

48. Perkins ND. The diverse and complex roles of NF-kB subunits in cancer. Nat Rev Cancer. 2012 Jan 19;12(2):121-32. doi: 10.1038/ $\operatorname{nrc} 3204$.

49. Rahman M, Kundu, JK, Shin JW, Na HK, and Surh YJ. Docosahexaenoic acid inhibits UVB-induced activation of NFkappaB and expression of COX-2 and NOX-4 in HR-1 hairless mouse skin by blocking MSK1 signaling. PLoS One. 2011;6(11):e28065. doi: 10.1371/journal.pone.0028065.

50. Patterson WL, Georgel PT. Breaking the cycle: the role of omega-3 polyunsaturated fatty acids in inflammation-driven cancers. Biochem Cell Biol. 2014 Oct;92(5):321-8. doi: 10.1139/bcb-20130127.

51. Smuder AJ, Min K, Hudson MB, Kavazis AN, Kwon OS, Nelson WB, Powers SK. Endurance exercise attenuates ventilator-induced diaphragm dysfunction. J Appl Physiol (1985). 2012 Feb;112(3):50110. doi: 10.1152/japplphysiol.01086.2011.

52. Mcguinness J, Neilan TG, Sharkasi A, Bouchier-hayes D, Redmond JM. Myocardial protection using an omega-3 fatty acid infusion: quantification and mechanism of action. J Thorac Cardiovasc Surg. 2006 Jul;132(1):72-9. doi: 10.1016/j.jtcvs.2005.10.061.

\section{Acknowledgements}

To Silvia Regina Batistuzzo de Medeiros, $\mathrm{PhD}$ (Full Professor, Department of Biological Sciences, UFRN) and Leonam Gomes Coutinho, PhD (UFRN) for technical support; Nelson Matias, Maria Silvandira França Pinheiro, Maria do Socorro F. Monte and Conceição da Silva Martins for their helpful technical assistance.

\section{Correspondence:}

Ana Paula Bomfim Soares Campelo

Departamento de Cirurgia

Universidade Federal do Ceará

Rua Professor Costa Mendes, 1608/3 andar

60430-140 Fortaleza - CE Brasil

Tel.: (55 85)3288-8063

Fax: (55 85)3288-8064

anapaulacampelo@bol.com.br

sbpana@bol.com.br

Received: Feb 10, 2015

Review: Apr 11, 2015

Accepted: May 9, 2015

Conflict of interest: none

Financial sources: CNPq and FUNCAP

${ }^{1}$ Research performed at Nutrigenomic Laboratory, Postgraduate Program in Surgery, Department of Surgery, Federal University of Ceara (UFC), Fortaleza-CE, Brazil. Paulo Tutor: Roberto Leitão de Vasconcelos. 